\title{
Explorative Analysis on the Mortality Pattern of Wild Animals at Territorial Forest Division Jabalpur, India
}

\author{
Ranjeet Harne*, Somesh Singh, Amol Rokde and Devendra Podhade \\ School of wildlife Forensic and Health, NDVSU, Jabalpur-482001, MP, India \\ *Corresponding author
}

\begin{abstract}
Keywords
Mortality pattern, Free range, Rescue, Territorial Forest Division

Article Info

Accepted:

14 December 2018 Available Online: 10 January 2019 teams in Non Protected Areas of Territorial Forest Division Jabalpur, Madhya Pradesh. A total of 104 deaths were recorded in seventeen different species of wild animals during the period from April 2015 - March 2017. The cause specific mortality was determined on the basis of data available from primary and secondary resources. The history and pathoanatomical changes observed at necropsy were recorded among animals brought at the School of wildlife Forensic and Health, NDVSU, Jabalpur, MP, India. The prime cause of deaths among wild animals were traumatic shock $(42.31 \%)$, followed by respiratory failure (15.38\%), drowning (13.46\%), hypovolemic shock $(3.85 \%)$, lung oedema $(1.92 \%)$ and septicaemia (1.92\%), while capture myopathy, electrocution and heat stroke were also reported each at the level of $(0.96 \%)$. Remaining $18.27 \%$ of the carcasses showed autolytic changes. It is necessary to conduct periodic studies on the mortality pattern among wild animals to know the factors affecting their survival and take steps to prevent large scale morbidity and mortality. The study also emphasises the significance of scientific handling during rescue operations in prevention of animal mortalities at Territorial Forest Divisions.
\end{abstract}

\section{A B S T R A C T}

A study was conducted to know the mortality pattern in wild animals received from rescue

\section{Introduction}

The wild animals and plants are important constituents of ecosystem and are essential to maintain equilibrium of various natural processes like temperature, rainfall, soil fertility etc. Uncontrollable human population growth leading to the industrialization and urbanization is rapidly replacing natural habitat, local vegetation and decreasing free space for wild animal's day by day (Donald al., 2004). This inter-specific competition for resources between human and wild animals has caused a decline in population of free range wild animals. The growing livestock population has created a competition for feed and fodder by overgrazing surrounding forest area causing a local decline in the population of wild herbivores (Mishra et al., 2003). The seasonal variation also causes a change in their diet and prey so these wild animals move from one place to other in search of prey which exposes them to two different adverse conditions like road accidents and humanwildlife conflict leading to more mortality of animals (Patterson et al., 2004). 
Wildlife mortality due to chasing by dogs, injury, felling in canal, heat stress and road accidents have caused considerable damage to their population in non protected areas in the past years. The condition is more critical in and around non protected areas of developing urban settings. Unfortunately, systemic studies on the mortality pattern in non protected areas are scarce and those available focused primarily on a few large mammals. Nevertheless, many species are found as victims and their mortality is probably underestimated. The analysis on mortality pattern in free range wild animal population is bit challenging because most such deaths go unobserved. Moreover, it is also difficult to diagnose the cause of mortality, weather it is natural or due to unnatural factors. Therefore, the present study was conducted to explore the mortality pattern and causes of deaths among wild animals received from rescue teams at Territorial Forest Division Jabalpur.

\section{Materials and Methods}

The study area Jabalpur is located in the Mahakoshal region of Madhya Pradesh, India and geographically, located between latitude $23^{\circ} 10^{\prime} \mathrm{N}$ and $23^{\circ} 17^{\prime} \mathrm{N}$ and longitude $79^{\circ} 57^{\prime} \mathrm{E}$ and $79^{\circ} 95^{\prime} \mathrm{E}$. The work was carried in Territorial Forest Division Jabalpur during April 2015 - March 2017. The cause of death of animals died during this period was determined based on necropsy examination. Data were also collected from the primary resources (Singh and Sharma, 2011) and secondary resources (Cnossen, 1997). The necropsy examination and analysis of data was conducted at the School of Wildlife Forensic and Health, NDVSU, Jabalpur, MP, India.

\section{Results and Discussion}

Present study analyses a total of 104 death cases of wild animals out of which maximum deaths occurred due to traumatic shock
$(42.31 \%)$ followed by respiratory failure $(15.38 \%)$, drowning $(13.46 \%)$, hypovolemic shock $(3.85 \%)$, lung oedema $(1.92 \%)$ and septicaemia (1.92\%), while capture myopathy, electrocution and heat stroke were reported each at the level of $(0.96 \%)$. Autolytic changes were reported in $(18.27 \%)$ of the carcasses (Table 1, Fig. 1 and Plate 1).

Deaths of pariah kite, pangolin, porcupine, black buck and tigress cub were reported due to traumatic shock. The death of 2 leopards was reported due to respiratory failure, while autolytic changes were recorded in other 2 carcasses. The necropsy of 3 cobras revealed their deaths due to respiratory failure. Carcasses of a sand boa and a crocodile were putrefied and showed autolytic changes. Traumatic shock and electrocution were the causes of mortality in common langur. Among peafowl the mortality was reported due to traumatic shock in 2 and lung oedema in 1; while autolytic changes were reported in 1 carcass.

The necropsy findings in chital showed maximum percentage of animals dying due to traumatic shock $(50.88 \%)$ followed by respiratory failure $(14.04 \%)$, hypovolemic shock $(7.02 \%)$, drowning (3.51\%); capture myopathy, lung oedema, septicaemia and heat stroke each three at the level of $(1.75 \%)$; while $17.54 \%$ of the carcasses showed autolytic changes.

The necropsy findings in barking deer showed maximum animals dying due to traumatic shock $(50 \%)$, followed respiratory failure and drowning each at the level of $16.67 \%$; while autolytic changes were reported in $16.67 \%$ of the carcasses. Death of sambhar was reported due to traumatic shock $(50 \%)$ and respiratory failure $(50 \%)$. Septicaemia was recorded in carcass of a nilgai. Traumatic shock $(25 \%)$ and autolytic changes (75\%) were seen in wild boars (Table 1, Fig. 1 and Plate 1). 
Table.1 Mortality pattern in wild animal during 2015-17

\begin{tabular}{|c|c|c|c|c|c|c|c|c|c|c|c|c|}
\hline $\begin{array}{l}\text { S. } \\
\text { No }\end{array}$ & Species & $\begin{array}{c}\text { Traumatic } \\
\text { shock } \\
\text { No. }(\%)\end{array}$ & $\begin{array}{c}\text { Respiratory } \\
\text { Failure } \\
\text { No. }(\%)\end{array}$ & $\begin{array}{c}\text { Hypovolemic } \\
\text { Shock } \\
\text { No. (\%) }\end{array}$ & $\begin{array}{c}\text { Capture } \\
\text { myopathy } \\
\text { No. }(\%)\end{array}$ & $\begin{array}{l}\text { Autolytic } \\
\text { changes } \\
\text { No. }(\%)\end{array}$ & $\begin{array}{c}\text { Drowning } \\
\text { No. }(\%)\end{array}$ & $\begin{array}{c}\text { Lung } \\
\text { oedema } \\
\text { No. }(\%)\end{array}$ & $\begin{array}{c}\text { Septicaemia } \\
\text { No. }(\%)\end{array}$ & $\begin{array}{c}\text { Electrocution } \\
\text { No. }(\%)\end{array}$ & $\begin{array}{c}\text { Heat } \\
\text { stroke } \\
\text { No. }(\%)\end{array}$ & $\begin{array}{c}\text { Total } \\
\text { Number }\end{array}$ \\
\hline 1. & Chital & $29(50.88)$ & $08 \quad(14.04)$ & $04(7.02)$ & $1(1.75)$ & $10(17.54)$ & $02(3.51)$ & $01(1.75)$ & $01(1.75)$ & - & $01(1.75)$ & 57 \\
\hline 2. & Barking deer & $03(50)$ & $01(16.67)$ & - & - & $01(16.67)$ & $01(16.67)$ & - & - & - & - & 06 \\
\hline 3. & Black buck & $01(100)$ & - & - & - & - & - & - & - & - & - & 01 \\
\hline 4. & Sambar & $01(50)$ & $01(50)$ & - & - & - & - & - & - & - & - & 02 \\
\hline 5. & Nilgai & - & - & - & - & - & - & - & $01(100)$ & - & - & 01 \\
\hline 6. & Wild boar & $01(25)$ & - & - & - & $03(75)$ & - & - & - & - & - & 04 \\
\hline 7. & $\begin{array}{l}\text { Rhesus } \\
\text { macaque }\end{array}$ & - & $01(8.33)$ & - & - & - & $11(91.67)$ & - & - & - & - & 12 \\
\hline 8. & $\begin{array}{l}\text { Common } \\
\text { langur }\end{array}$ & $01(50)$ & - & - & - & - & - & - & - & $01(50)$ & - & 02 \\
\hline 9. & Peafowl & $02(50)$ & - & - & - & $01(25)$ & - & $01(25)$ & - & - & - & 04 \\
\hline 10. & Pariah kite & $01(100)$ & - & - & - & - & - & - & - & - & - & 01 \\
\hline 11. & Pangolin & 03 (100) & - & - & - & - & - & - & - & - & - & 03 \\
\hline 12. & Porcupine & $01(100)$ & - & - & - & - & - & - & - & - & - & 01 \\
\hline 13. & Crocodile & - & - & - & - & $01(100)$ & - & - & - & - & - & 01 \\
\hline 14. & Tigress (cub) & $01(100)$ & - & - & - & - & - & - & - & - & - & 01 \\
\hline 15. & Leopard & - & $02(50)$ & - & - & $02(50)$ & - & - & - & - & - & 04 \\
\hline 16. & Cobra & - & $03(100 \%)$ & - & - & - & - & - & - & - & - & 03 \\
\hline 17. & Sand boa & - & - & - & - & $01(100 \%)$ & - & - & - & - & - & 01 \\
\hline & Grand Total & $44(42.31)$ & $16(15.38)$ & 04 (3.85) & $01(0.96)$ & 19 (18.27) & $14(13.46)$ & 02 (1.92) & 02 (1.92) & $01(0.96)$ & $01(0.96)$ & 104 \\
\hline
\end{tabular}


Fig.1 Necropsy changes in wild animals recovered during rescue operation (2015-2017)

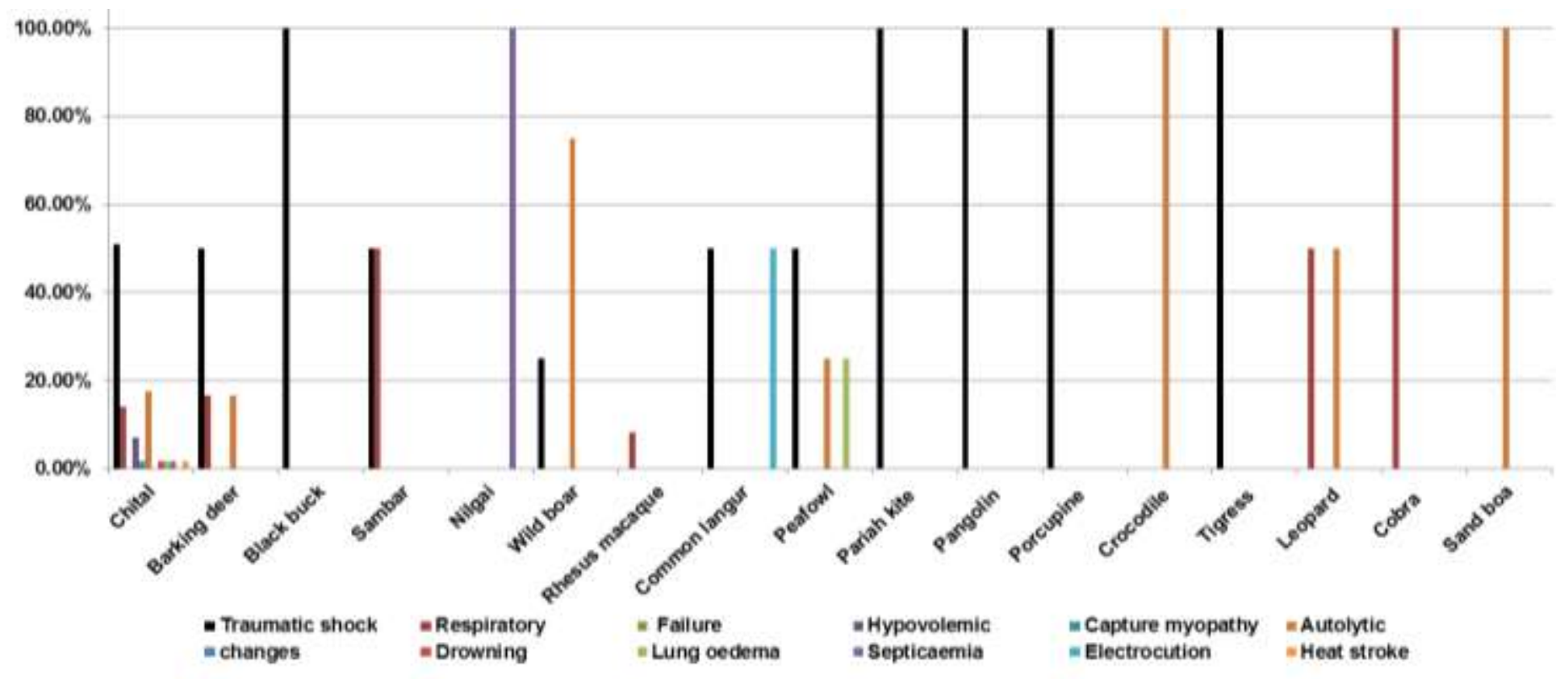


Plate.1 Necropsy examination of wild animals

(a) Extensive hemorrhages in medial aspect of neck region due to severe trauma in a chital (b) Dog bite injuries in perineum and medial aspect of thigh in a chital

(c) Congestion in respiratory tract of a cobra

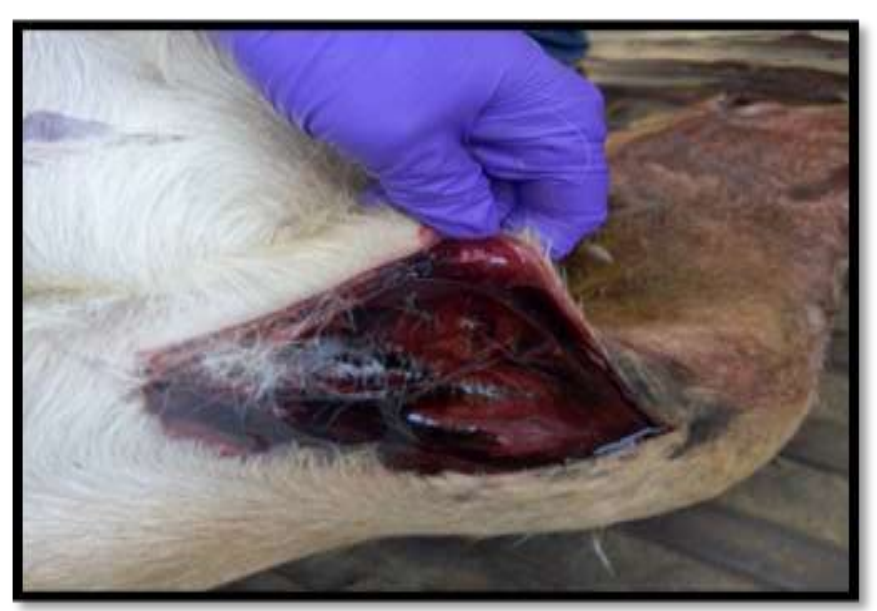

(a)

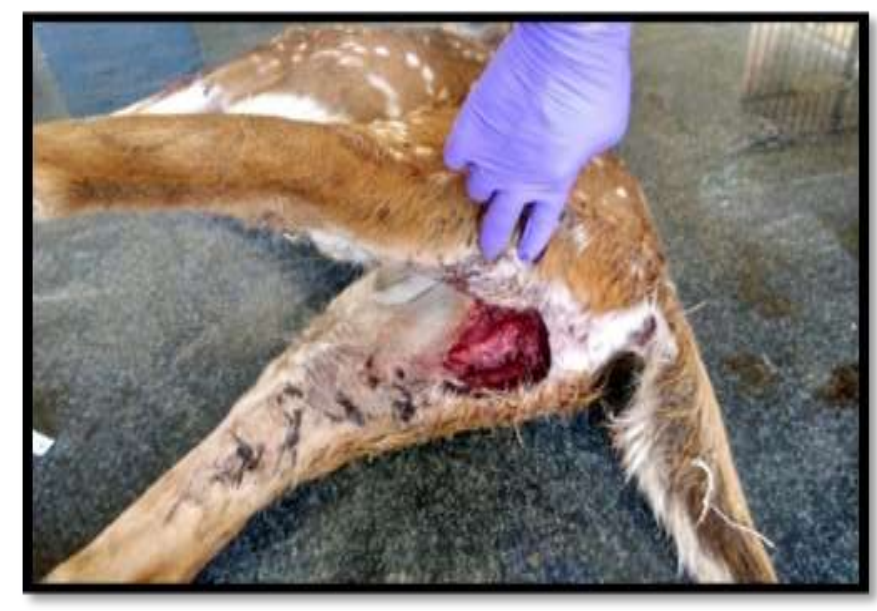

(b)

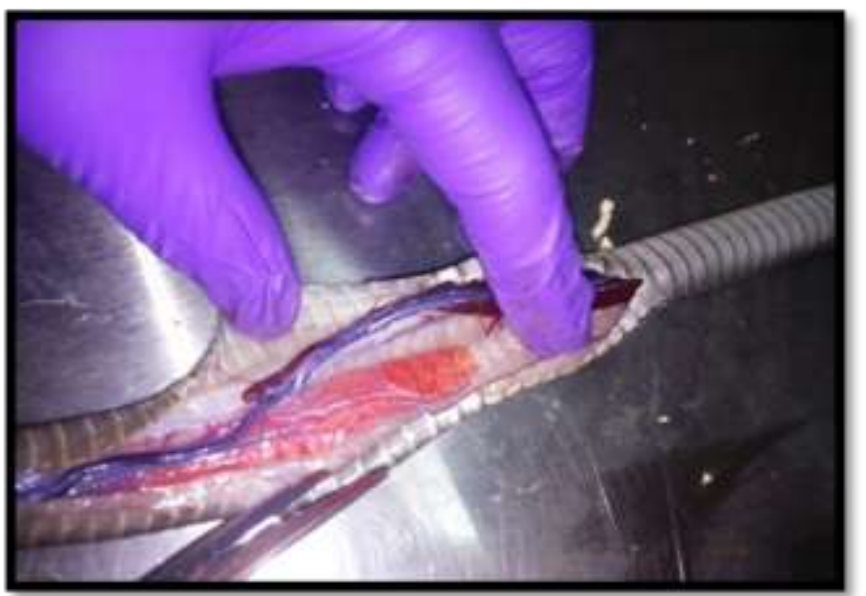

(c) 
Among animals died while being brought for treatment, the unscientific transportation, improper handlings leading to skin abrasion, lacerations, muscular injury, hoof injury, antler injury, strangulation due to strings and fracture were recorded. During the necropsy examinations major lesions reported were skin abrasions, lacerations, subcutaneous congestion, haemorrhages, muscular injuries, fractures and haemothorax. The findings of the investigation of Swamy et al., (2016) reports most of the mortalities in free ranging wild animals due to respiratory failure resulting from road trauma, drowning, suffocation and strangulation.

Similar kind of studies was conducted by Kumar et al., (2012) on the mortality causes in 113 wild animals died at Shivalik hills in Himachal Pradesh. The necropsy findings revealed musculoskeletal injuries in $68.14 \%$ (77); more specifically fractures $37.16 \%$ (42) and fatal traumatic injuries $30.97 \%$ (35) as most common cause of mortality in all the animals. Mortality due to septicemic conditions was observed in $8.84 \%$ (10) of died animals. Obendorf (1983) conducted necropsy of 44 wild koalas (24 males and 20 females) from several locations in Victoria, Australia and the commonest reason of deaths were traumatic injuries resulting from motor vehicle accidents and intra-specific conflict. The strong association between wild animals, human beings and domestic animals has become important now-a-days as there was found involvement of wild animals in transmission of certain inter-species as well as intra-species diseases.

Acharjyo and Rao (1987) documented the rescue cases in and around Biological Park, Bhubaneshwar which reports mortality due to animal chasing by dogs followed by falling into moat. The authors also reported $4.3 \%$ mortality during rescue due to drowning in a period of five year. Arora (2003) proposed the chance for variation in health status from normal range due to capture stress i.e. chemical immobilization, nutritional and health status. The former factor is difficult to be eliminated and depends mostly on the nature of habitation (wild, semi-captive, captive) and the extent of domestication.

Among rhesus macaques maximum percentage of animals died due to drowning (91.67\%), followed by respiratory failure $(1.75 \%)$. The necropsy findings in common langur showed equal percentage of animals dying due to traumatic shock and electrocution with each at the level of $(50 \%)$. Sengar et al., (2014) reported a case of electrocution injury in a common langur wandering in search of food and water. They proposed that electric current passing through the animal body may cause coma and death, if the current is sufficiently strong. Nath and Chakraborty (2013) reported 27 deaths in six different species of non human primates.

The necropsy findings in a pariah kite showed death of the bird due to traumatic shock. Arora (2003) emphasized that capturing wild birds causes injury, shock and death in millions each year. He further stressed that transportation of birds is not risk free particularly during summers.

It is the general behaviour of an animal to escape while being captured. However, deer are at high risk of stress, shock and capture myopathy while they are being handled prior to their transport from one place to another. The risk increases if the deer with antlers or in velvet are allowed to struggle during their capture or restraint and the process is carried out in hot weather. The study findings were indicative of various kinds of injuries and stressful conditions animals suffer during rescue operations, which can be improved through scientific handling and transportation of animals.

In conclusion, the study signified that the analysis on mortality pattern of wild animals at Territorial Forest Divisions is of utmost importance to reveal the factors affecting animal survival, so as to take measures to prevent large scale morbidity and mortalities and ensure effective wildlife conservation. For 
this purpose it is important to perform scientific necropsy examination of each wild animal to know the causes of deaths and take precautionary measures to prevent large scale mortalities. Lack of proper handling of animals could lead to animal mortalities. The success of rescue operations depends chiefly upon the scientific handling of animals which not only avoid distresses in wild animals but also prevent mortalities. It is need of the hour to prepare and adopt standard operating procedures for rescue and handling of wild animals at Territorial Forest Divisions and develop trained human resources for handling such situations.

\section{Acknowledgement}

Authors are thankful to the authorities of M.P. Forest Department and Nanaji Deshmukh Veterinary Science University, Jabalpur for providing necessary support to carry out this research work.

\section{References}

Acharjyo, L.N. and Rao, A.T. (1987). Mortality pattern in some Indian captive wild ruminants. Ind. J. Ani. Sci., 57: 430-435.

Arora, B. M. (2003). Indian Wildlife Diseases and Disorders, $1^{\text {st }}$ Edn., Bytes and Bytes Printing, Bareilly, pp 449-581.

Cnossen, C. (1997). Secondary Research: Learning Paper 7, School of Public Administration and Law, the Robert Gordon University, Aberdeen, United Kingdom.

Donald, L.B., Kelly, A. D. (2004). Morbidity and mortality of urban wildlife in the Midwestern United States, Proceedings of $4^{\text {th }}$ International Urban Wildlife Symposium. Online: http://cals.arizona. edu/ pubs/adjunct/snr0704/
Kumar, V., Kumar, V and Raj, A. (2012). Mortality in free range rescued wild animals of Shivalik Hills in Himachal Pradesh, India. Vet. Sci. Dev., 1(2): 4-6.

Mishra, C., Allen, P., McCarthy, T. (2003). The role of incentive programs in conserving the Snow Leopard. Con. Bio., 17:151220.

Nath, B.G. and Chakraborty, A. (2013) Mortality pattern in non human primates in Assam, India. Vet. World 6(1): 39-41.

Obendorf, D.L. (1983). Causes of mortality and morbidity of wild koalas, Phascolarctos cinereus (Goldfuss) in Victoria, Australia. $J$ of Wild Dis, 19(2): 123-131.

Online https://jura2.eee.rgu.ac.uk/dsk5/ research /material/resmeth

Patterson, B. D., Kasiki, S. M., Selempo, E. and Kays, R. W. (2004). Livestock predation by lions (Panthera leo) and other carnivores on ranches neighboring Tsavo National Park, Kenya. Bio Con., 16: 119:507.

Sengar, A., Shrivastav, A.B., Rokde, A. and Singh, S. (2014). Electrocution management in a Langur (Semnopithecus entellus). J of Wild Res, 2(1): 7-8.

Singh, R. and Sharma, R. K. (2011). Statistical Methods and Experimental Design, $1^{\text {st }}$ Edn. Aman Publishing House, Meerut, pp13-19.

Swamy, M., Rajput, N., Jadhav, K.K., Joshi, H.R and Shrivastav, A.B. (2016). Histopathology of asphyxia in free ranging wild animals. In: National Symposium on Innovative approaches for Diagnosis and Control of Emerging and Re-emerging diseases of Livestock, Poultry and Fish, Anjora, 9-11 Nov. 2016, Indian Association of Veterinary Pathologists (IAVP), p. 285.

\section{How to cite this article:}

Ranjeet Harne, Somesh Singh, Amol Rokde and Devendra Podhade. 2019. Explorative Analysis on the Mortality Pattern of Wild Animals at Territorial Forest Division Jabalpur, India. Int.J.Curr.Microbiol.App.Sci. 8(01): 2247-2253. doi: https://doi.org/10.20546/ijcmas.2019.801.235 